\title{
Proposta de instrumento de avaliação do desenvolvimento da atividade lúdica segundo abordagem Histórico-Cultural
}

\author{
Proposal of a playing activity development evaluation under \\ Historical-Cultural approach
}

Camila Borges ${ }^{1}$

Caio Morais ${ }^{2}$

\section{RESUMO}

Neste artigo, apresenta-se uma proposta inicial do Protocolo de Avaliação do Desenvolvimento da Atividade Lúdica. É o primeiro instrumento de investigação psicológica sob o referencial teórico da psicologia histórico-cultural, da teoria da atividade e do desenvolvimento mental por etapas. O estudo utilizou uma metodologia teórico-prática, conduzindo uma investigação de conceitos como "desenvolvimento", "idades psicológicas" e "jogo", conforme marco teórico delimitado. A revisão de literatura norteou a construção do protocolo, o qual foi examinado por cinco pareceristas especialistas na área. Abordando o cenário das avaliações psicológica e neuropsicológica qualitativas, apresenta-se a estrutura do instrumento, tal como construído, e as considerações emitidas pelas avaliadoras. O protocolo foi bem avaliado e recebeu críticas, sugestões e recomendações importantes, as quais foram empregadas em sua revisão e correção. Busca suprir a carência de instrumentos que permitam conhecer o estado ontológico do desenvolvimento do brincar como importante marcador do desenvolvimento infantil e da idade psicológica, e que possam contribuir à análise preventiva. Também se dispõe a apresentar um diferencial que seria a

ABSTRACT

This article presents an initial proposal for the Protocol for the Evaluation of the Development of Playful Activity. It is the first instrument of psychological investigation under the theoretical framework of historical-cultural psychology, activity theory and mental development in stages. The study used a theoretical-practical methodology, conducting an investigation of concepts such as "development", "psychological ages" and "play", according to a defined theoretical framework. The literature review guided the construction of the protocol, which was examined by five expert reviewers in the area. Approaching the scenario of qualitative psychological and neuropsychological evaluations, the structure of the instrument, as constructed, and the considerations issued by the evaluators are presented. The protocol was well evaluated and received important criticisms, suggestions and recommendations, which were used in its review and correction. It seeks to supply the lack of instruments that allow to know the ontological state of the development of play as an important marker of child development and psychological age, and that can contribute to preventive analysis. It is also willing to present a differential that would be the characterization of the ZDP for greater
\end{abstract}

\footnotetext{
${ }^{1}$ Psicóloga. Mestre em Diagnóstico e Reabilitação Neuropsicológica pela BUAP (Puebla, México). https://orcid.org/0000-0002-8884-355X.

${ }^{2}$ Psicólogo. Mestre em Diagnóstico e Reabilitação Neuropsicológica pela BUAP (Puebla, México). Sócio-fundador e administrador do Instituto Luria de Neuropsicologia (Salvador-BA). Professor da pós-graduação em neuropsicologia da Faculdade Ruy Barbosa (Salvador-BA). Assessor de acessibilidade da SECADI/MEC. ORCID: https://orcid.org/0000-0002-0839-0854. E-mail: morais_caio@yahoo.com.br.
} 
caracterização da ZDP para maior compreensão da criança e não sua patologização. Espera-se que o presente trabalho seja seguido por esforços semelhantes de construção de instrumentos que diminuam a lógica patologizante cada vez mais marcante na sociedade atual.

Palavras-chave:

Avaliação.

Desenvolvimento. Jogo. Idade psicológica. understanding of the child and not its pathologization. It is expected that the present work will be followed by similar efforts to build instruments that diminish the pathologizing logic that is increasingly striking in today's society.

Keywords: Evaluation. Development. Play. Psychological age.

\section{Introdução}

A avaliação psicológica, conforme Artigo $1^{\circ}$ da resolução 09/2018 do Conselho Federal de Psicologia (CFP), é uma investigação estruturada de fenômenos psicológicos que provê informações para a pessoa, grupo ou instituição que solicita a avaliação de acordo com suas demandas específicas. $\mathrm{O}$ Artigo $2^{\circ}$ da mesma resolução ainda aclara que o psicólogo deve tomar decisões com base em métodos, técnicas e instrumentos reconhecidos pela comunidade científica da psicologia, podendo também recorrer a procedimentos auxiliares/complementares, como instrumentos não psicológicos e protocolos ou relatórios multiprofissionais, desde que se respeitem as diretrizes do Código de Ética da profissão. Segundo o Sistema de Avaliação de Testes Psicológicos (SATEPSI), como explicitado no Artigo $4^{\circ}$ da mesma resolução, os testes psicológicos são instrumentos que permitem "identificar, descrever, qualificar e mensurar características psicológicas”, valendo-se de procedimentos sistemáticos de observação e descrição aprovados pela comunidade científica.

Se tomarmos como recorte o público infantil/infanto-juvenil, o SATEPSI (2020) disponibiliza uma lista com 154 instrumentos favoráveis, dentre os quais 23 abrangem exclusivamente essa faixa etária, considerando uma idade mínima de 2 anos e meio e uma idade máxima de 16 anos. Dentre testes psicométricos e projetivos, os principais constructos investigados são inteligência (8), personalidade (5), habilidades e competências (3) processos neuropsicológicos (2), motivações (2) e outros (3) como lateralidade, maturação percepto-motora e autoconceito. 
Cabe lembrar que a elaboração de instrumentos de avaliação se dá de acordo com os princípios teórico-metodológicos das abordagens que representam na psicologia. Nesse sentido, refletir sobre os métodos de trabalho científico na psicologia, considerando seus diferentes objetos de estudo, também pode levar-nos a uma melhor compreensão sobre o processo de construção e uso de testes psicológicos e nosso papel enquanto psicólogos nesse cenário. Solovieva e Quintanar Rojas (2019) apresentam uma comparação entre os três principais objetos de estudo da psicologia, considerando o papel do pesquisador, o método utilizado para coleta de dados, a forma de apresentação desses dados e a possibilidade de generalização dos mesmos.

Para estudar processos cognitivos, o método que se utiliza é o de registro e medição, no qual o pesquisador não intervém na realização do estudo, mas apenas registra os dados numéricos que, após um tratamento estatístico, podem ser generalizados (SOLOVIEVA; QUINTANAR ROJAS, 2019). As provas psicométricas são construídas dentro desse princípio metodológico, de maneira que sua aplicação requer a imparcialidade do psicólogo que lê as instruções e as perguntas e registra as respostas que serão comparadas aos resultados esperados obtidos em uma mostra populacional representativa.

Para estudar a experiência interna ou a construção de significados, o método mais utilizado é a análise do discurso produzido em resposta a um estímulo do pesquisador, que analisa os dados segundo a literatura da sua abordagem e as experiências prévias do sujeito, razão pela qual os dados obtidos são pouco generalizáveis e a metodologia é mais utilizada para estudo de caso único (SOLOVIEVA; QUINTANAR ROJAS, 2019). Nesse caso, identifica-se uma relação com a elaboração e aplicação de técnicas projetivas, nas quais se utilizam imagens ou desenhos feitos pelo próprio paciente como ponto de partida para a produção de um discurso que será analisado pelo psicólogo de acordo com sua orientação teórica.

Por último, se consideramos a combinação dos objetos de estudo anteriores, temos o objeto da psicologia histórico-cultural proposto por Vygotski: o estudo do desenvolvimento da conduta e seu significado dentro da atividade cultural humana. Buscando, para isso, o entendimento das funções especificamente 
humanas (as funções psicológicas superiores) considerando-as como produtos da cultura e da história. O método que ele inaugura é conhecido como "genéticoexperimental ou formativo" (VYGOSTSKI, 2012c) e consiste em reproduzir artificialmente o processo de desenvolvimento psicológico, segundo as leis do desenvolvimento ontogenético, determinado pela assimilação (interiorização) dos meios de orientação dos processos psíquicos (signos) produzidos na e pela experiência cultural humana. Isso acontece em duas etapas: primeiro interpsicológica, na interação com um sujeito mais experiente na atividade coletiva e social, e depois intrapsicológica, como propriedade interna na atividade individual (VYGOSTSKI, 2012b). Dessa maneira, o pesquisador necessita intervir para provocar o processo formativo e os dados obtidos podem ser registrados de maneira descritiva e numérica e sua interpretação se dá fundamentalmente pelos conceitos dessa abordagem, de maneira que não poderiam ser analisados somente pelo tratamento estatístico dos dados. Seria precisamente graças às generalidades do processo formativo descritas na literatura que os dados obtidos em um estudo poderiam ser também generalizáveis (SOLOVIEVA; QUINTANAR ROJAS, 2019).

Não existem dúvidas quanto ao predomínio de produção e uso de instrumentos psicométricos entre os psicólogos, porém é necessário saber que o que se avalia através desse método são as habilidades já consolidas, o que dentro da psicologia histórico-cultural é entendido como Zona de Desenvolvimento Real (ZDR). Não obstante, nesta perspectiva teórica, o papel da avaliação não termina por aí, pois estaria incompleta. Uma contribuição importante do psicólogo histórico-cultural é a compreensão da Zona de Desenvolvimento Proximal (ZDP), quer dizer, dos processos que se encontram em vias de maturação e que só são acessíveis através da mediação (VYGOTSKI, 2012b). Desta forma, faz falta contar com instrumentos que permitam sistematizar as observações do profissional (que tem uma participação ativa na avalição e que por isso mesmo se utiliza a expressão "avaliação interventiva") no que diz respeito ao processo de execução do paciente, mais do que as suas respostas.

$\mathrm{Na}$ última década, na psicologia histórico-cultural, alguns instrumentos qualitativos destinados a crianças (de cinco a doze anos) foram desenvolvidos, em 
países como Rússia, México e Finlândia, atendendo a uma demanda crescente, em contexto clínico, por solucionar questões relacionadas aos processos de educação e aprendizagem, muito embora exista uma carência da elaboração de procedimentos específicos para avaliar cada idade psicológica (SOLOVIEVA; QUINTANAR ROJAS, 2013). Desenvolver instrumentos desse tipo permite ampliar o trabalho do psicólogo, tornando o processo avaliativo mais rico em informações e possibilitando a construção de programas de estimulação mais eficientes. Além disso, instrumentos que contemplem uma idade inicial menor (desde o primeiro ano de vida) tem muito a contribuir para o diagnóstico precoce da criança, servindo de prevenção a dificuldades futuras (GLOZMAN, 2014).

Buscando suprir a essa carência de instrumentos que permitam avaliar o desenvolvimento da criança por idade psicológica e que possam contribuir para o diagnóstico preventivo, foi desenvolvido pelos autores do presente artigo, no Programa de Iniciação Científica e Tecnológica (PICT 2014/2015), da Faculdade Ruy Barbosa, em Salvador-Bahia, o Protocolo de Avaliação do Desenvolvimento da Atividade Lúdica. Esse instrumento foi elaborado sob o referencial teórico da psicologia histórico-cultural, tomando como eixo teórico principal a periodização do desenvolvimento infantil proposta Vygotski, a teoria da atividade, de Leontiev, e a teoria do jogo, de Elkonin. Esse artigo está dividido em três seções. A primeira tem o objetivo de apresentar o eixo teórico que embasou a construção do protocolo, reconhecendo a importância do jogo para o desenvolvimento integral da criança. A segunda tem o objetivo de apresentar o processo de construção do protocolo, discutindo sua metodologia. Por último, a terceira seção tem o objetivo de comentar as contribuições da aplicação do protocolo na avaliação psicológica nos contextos da clínica e da educação infantil.

\section{O desenvolvimento integral da criança e as contribuições da atividade lúdica}

O conceito de idade psicológica foi apresentado por Vygotski em 1932 (LAZARETTI, 2013), desenvolvendo o que foi problematizado em 1931 no texto 
"O problema da idade cultural" (PRESTES, 2010; VYGOTSKI, 2012b), referindose ao desenvolvimento cultural da criança, onde personalidade e intelecto caracterizam duas linhas de desenvolvimento e formam uma unidade complexa que mantém relações recíprocas. Assim, o desenvolvimento da criança se dá pelo domínio das formas de atividades humanas desenvolvidas historicamente, o que permeia a construção da sua personalidade e consciência, de forma dinâmica através de estágios ou períodos (VYGOTSKI, 2012a; CHAIKLIN, 2019). No desenvolvimento se alternam períodos estáveis (idades psicológicas) e críticos (crises). Nas palavras de Vygotski (2018, p.23), “[a] idade nada mais é do que um determinado ciclo de desenvolvimento fechado, separado dos outros ciclos, que se diferencia por seus tempos e conteúdos específicos". Vygotski (2012a) descreveu quatro idades psicológicas que marcam o desenvolvimento da criança: Primeiro ano (de zero a um ano); Primeira infância (de um a três anos); Pré-escolar (de três a seis anos); Escolar (de seis a doze anos). O conteúdo de cada idade psicológica se configura a partir de quatro componentes: 1. Atividade-guia; 2. Neoformações; 3. Situação social; 4. Linhas do desenvolvimento.

Para cada idade há uma atividade-guia, ou seja, aquela que determina as mudanças básicas em sua psique, preparando-a para o próximo estágio (LEONTIEV, 2010a, 2010b). As neoformações são formações psicológicas novas, que aparecem no final de cada idade. Elas põem em evidência as transformações da relação do sujeito com a realidade externa e consigo mesmo e indicam a necessidade de passar ao estágio seguinte (VYGOTSKI, 2012a). O ponto de partida que transforma as necessidades e motivações da criança em cada idade psicológica e a impulsiona a uma nova etapa se apresenta na situação social do desenvolvimento, caracterizada pelo lugar que a criança ocupa na sociedade (historicamente determinado) e na família (BOZHOVICH, 2004, 2009; VYGOTSKI, 2012a). O motivo de cada atividade-guia se manifesta nas linhas do desenvolvimento psicológico, uma afetivo-emocional e outra técnico-operacional, que se alternam ainda que mantendo uma interação dinâmica (unidade afeto-intelecto), ou seja, quando uma delas é a linha geral (a principal, a regente), a outra opera como linha subordinada. Quando a linha geral é afetivo-emocional, o interesse da criança está voltado para as relações e experiências sociais (integra o sistema de relação criança- 
outro social). Se, por outro lado, a linha geral é técnico-operacional, o interesse estará vinculado à experiência prática (integra o sistema de relação criança-objeto social) (ELKONIN, 2009a; SOLOVIEVA; QUINTANAR ROJAS, 2012).

Vygotski (2018) menciona que o curso do desenvolvimento opera pela "lei da metamorfose", referindo-se às transformações qualitativas que se apresentam no desenvolvimento infantil e, para compreendê-lo corretamente, é importante considerar que, no desenvolvimento, sempre surge algo novo e que esse "novo" aparece nas etapas precedentes do momento atual do desenvolvimento em que a criança se encontra. Assim, "[...] o passado, no futuro, tem uma influência iminente no surgimento do presente" (VYGOTSKI, 2018, p.36). O curso do desenvolvimento é conduzido fundamentalmente pelas mudanças que ocorrem no sistema de relações humanas, ou seja, na situação social do desenvolvimento (LEONTIEV, 2010b). Essas mudanças têm um forte impacto na personalidade e consciência da criança e provocam transformações significativas que a conduzem a um novo período, sendo essa transição o que configura os períodos críticos, as crises descritas por Vygotski (2012a). Esse é o ponto fundamental dessa concepção de desenvolvimento: os períodos ou estágios estão determinados pelas transformações das condições histórico-sociais e não pela contagem cronológica do tempo. E as crises seriam momentos importantes de ruptura necessários ao desenvolvimento psicológico, pois seriam provocados pelos desafios socioculturais (ABRANTES; EIDT, 2019). A Figura 1 esquematiza o curso do desenvolvimento infantil.

Figura 1 - Esquema do curso do desenvolvimento infantil.

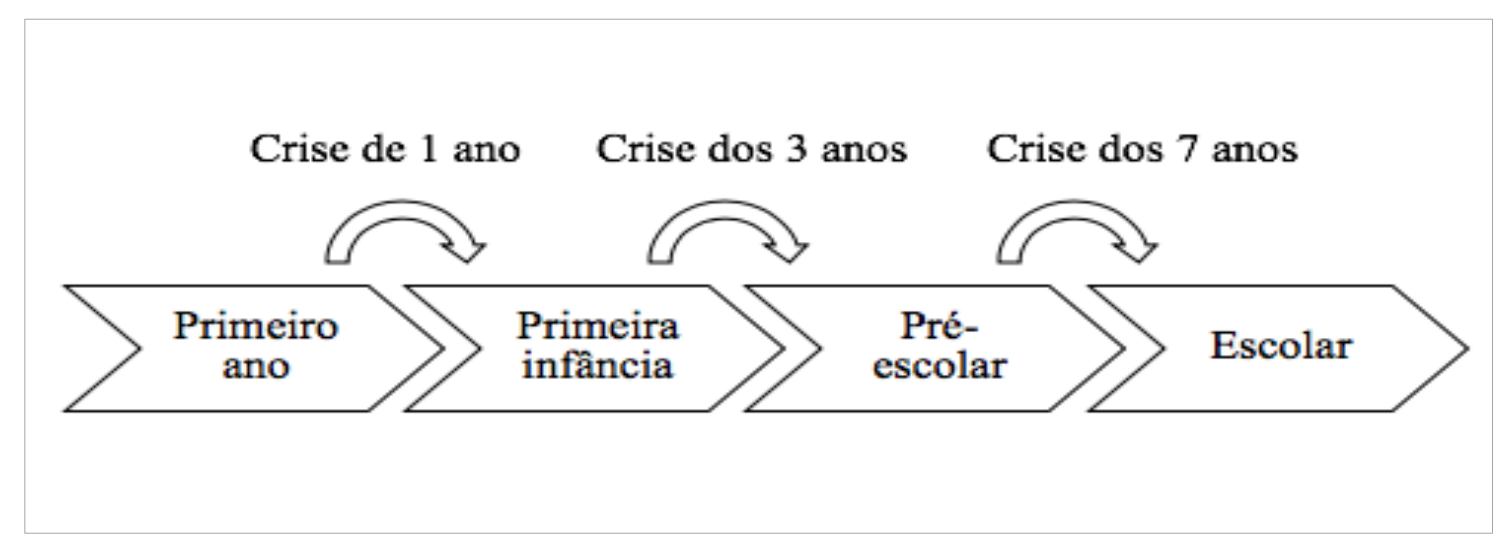

Fonte: Elaboração dos autores. 
Elkonin (2009b) agregou às idades psicológicas etapas de desenvolvimento do jogo, discutindo em seu livro, "Psicologia do Jogo", publicado originalmente em 1978 (LAZARETTI, 2013), os efeitos dessa atividade sobre o desenvolvimento psíquico da criança. O jogo é uma atividade objetiva, que se dá com base na percepção que a criança tem do mundo e dos objetos humanos, e é a via pela qual a criança se apropria da experiência cultural humana (ELKONIN, 2009b; LEONTIEV, 2010a; SHEINA; SMIRNOVA; RYABKOVA, 2017). O que caracteriza uma atividade objetiva é a capacidade de transformar o ambiente (físico ou social) e, ao mesmo tempo, transformar ao próprio sujeito que a realiza (GALPERIN, 2019). O protagonismo dessa atividade no desenvolvimento infantil se deve a que esta possibilita à criança o domínio de uma área mais ampla da realidade, que não lhe é diretamente acessível. Assim, a fantasia e a imaginação criam condições para a apropriação da realidade do modo que for possível à criança em dado período (LEONTIEV, 2010a).

Para Vygotski (2007, 2009), o jogo cria uma zona de desenvolvimento proximal, visto que contém tendências do desenvolvimento cognitivo, emocional e social. Nesse caso, reforça- se o papel do outro na formação dessa atividade tão importante para o desenvolvimento infantil que constitui a atividade-guia dos períodos "Primeira infância" e "Pré-escolar", entre o primeiro e o sexto ano de vida (SOLOVIEVA; QUINTANAR ROJAS, 2012). O adulto domina as ações objetais, as normas e regras socais e, na atividade conjunta com a criança, utiliza desses meios para orientar a criança na realidade circundante (ELKONIN, 2009b). Dessa forma, o jogo se desenvolve progressivamente e se faz cada vez mais complexo em suas características, contribuindo sempre às neoformações de cada idade.

Elkonin (2009b) descreve cinco etapas de desenvolvimento do jogo, as quais trazem contribuições importantes desde os primeiros meses de vida até a idade "Escolar". A primeira delas é o jogo de manipulação inespecífica, que surge durante o "Primeiro ano", por volta dos 05 meses e evolui de modo intimamente relacionado com o desenvolvimento das coordenações sensório-motoras, que contribuem às capacidades de fixação e seguimento ocular, integração olho-mão, preensão e 
palpação do objeto e percepção tridimensional deste, tão necessárias para que a criança possa manipular e atuar com os objetos (ELKONIN, 2009b). Através dessa atividade a criança poderá conhecer os objetos executando ações como segurar, passar de uma mão a outra, agitar, empurrar, jogar, levantar e puxar, as quais se denominam "inespecíficas" porque ocorrem para qualquer objeto, independentemente de sua função social (SOLOVIEVA; QUINTANAR ROJAS, 2012). Essas manipulações atendem a uma necessidade de estabelecer uma comunicação emocional com o outro (atividade-guia desse período), quem participa para ampliar as possibilidades de ação da criança, apresentar a ela novos objetos e animá-la a explorá-los (ELKONIN, 2009a).

$\mathrm{Na}$ "Primeira infância", ao final do primeiro ano, surge o interesse por aprender a manipular e utilizar os objetos sociais como instrumentos que possuem uma função socialmente elaborada. Sob mediação do outro, a criança obtém não só conhecimento prático, mas também o estímulo e o elogio, e assim aparece o jogo objetal, como atividade-guia desse período, caracterizado pela realização de ações práticas correspondentes aos objetos cotidianos (ELKONIN, 2009a, 2009b). Nesse sentido, o brinquedo oferecido à criança deve ser atrativo e determinar por seu tipo as ações possíveis de se realizar (SHEINA; SMIRNOVA; RYABKOVA, 2017). Nesse período, a percepção exerce uma força determinadora sobre a ação com objetos e, por isso, a criança costuma realizar ações repetidas com os mesmos objetos até que ela alcance a condição de agir independentemente daquilo que vê, o que está diretamente relacionado ao desenvolvimento da linguagem e sua função reguladora dos processos psíquicos (VYGOTSKI, 2007, 2009).

Ainda nesse período, a partir dos dois anos, as ações com objetos vão se tornando cada vez mais variadas e as crianças começam intencionalmente a experimentar novas formas de utilizar os objetos, produzindo novos resultados. Assim se inicia o jogo simbólico, no qual as ações simbólicas se tornam mais complexas gradativamente. Inicialmente, a criança transfere a ação com um objeto a outro. Isso acontece quando o jogo objetal se realiza com ações mais variadas. Por exemplo, a criança pode pentear a boneca, mas também penteia os ursinhos de pelúcia. Posteriormente, a criança transfere o significado de um objeto para outro, 
o que se observa na substituição dos objetos, primeiro satisfazendo uma necessidade de semelhança com o objeto representado, quando a força determinadora da percepção ainda está presente. Mais adiante, com a separação dos campos visual e semântico, a percepção perde sua força determinadora e os objetos substitutivos ganham a capacidade de significar outros completamente discrepantes, refletindo a abstração das características essenciais das coisas. A imaginação da criança permite criar e representar diferentes ações e objetos em sua ausência, o que inicialmente parte do modelo do adulto (ELKONIN, 2009b; SOLOVIEVA; GONZÁLEZ-MORENO; QUINTANAR ROJAS, 2015). Esse jogo estabelece, portanto, as bases para o pensamento abstrato e para a atividade voluntária, o que requer autoconcentração e autodeterminação para o controle do impulso imediato (VYGOTSKI, 2007, 2009).

Na idade "Pré-escolar", essas ações objetais e simbólicas que tiveram início no período anterior continuam a se desenvolver e configuram uma forma ainda mais complexa de jogo: o jogo temático de papéis sociais. Nenhum outro jogo ressalta tanto as funções sociais e o sentido da atividade das pessoas como esse. $\mathrm{O}$ interesse da criança volta-se ao adulto e seus atos, os quais são tomados como modelos. Em contraposição à relação criança-objeto social observada durante o período anterior, este período e consequentemente o jogo de papéis sociais (atual atividade-guia) está marcado pelo predomínio da relação criança-outro social (ELKONIN, 2009a). Para a representação das situações sociais reais de forma lúdica, a criança assume um papel, o que implica realizar ações específicas que o caracterizam. A situação imaginária que se estabelece e os papeis interpretados contêm em si, de forma implícita, as regras sociais de comportamento, o que oferece à criança a possibilidade de verificação da própria conduta, ainda que de maneira inconsciente (VYGOTSKI, 2007, 2009; ELKONIN, 2009b).

Esse jogo se estende por boa parte da infância, estando presente também na idade "Escolar", porém de forma mais complexa. Para melhor compreendê-lo, Elkonin (2009b) dividiu, didaticamente, o desenvolvimento de jogo de papéis em quatro níveis, os quais podem ser resumidos em dois estágios fundamentais: um que corresponde à faixa etária de três a cinco anos, abrangendo os dois primeiros 
níveis, e outro para a de cinco a sete anos, integrando os dois últimos. Todavia, a idade cronológica não é determinante, pois os experimentos realizados pelo autor apontam que crianças de uma mesma faixa etária podem estar em níveis distintos ou, até mesmo, em dois deles concomitantemente. O essencial para esta separação em dois estágios é a transição de conteúdo fundamental, do aspecto central do jogo, aquilo que a criança reconstitui a partir de sua atividade com os adultos. Antes determinado pelas ações objetais, de orientação social, correspondentes à lógica das ações reais, o conteúdo passa a ser delineado pelas relações sociais entre as pessoas e pelo sentido social da atividade, em correspondência às relações interpessoais reais (ELKONIN, 2009b).

Na idade "Escolar", a partir dos jogos de papéis complexos (correspondente ao nível 4), se desenvolve o jogo de regras. De acordo com Leontiev (2010a), o papel e a situação imaginária, antes explícitos, passam a ser implícitos, o que confere destaque às regras, que por sua vez passam a ser explícitas. Para que essa mudança ocorra é preciso que a criança já tenha se apropriado das regras dos papéis e compreenda sua necessidade e consequências (SOLOVIEVA; QUINTANAR ROJAS, 2012). A regra explícita exige uma consciência cada vez maior do objetivo da brincadeira e o respeito a essas regras favorece o desenvolvimento de relações positivas de cooperação e da capacidade de controlar o próprio comportamento e subordiná-lo a um propósito definido (LEONTIEV, 2010a). O Quadro 1 resume as características das idades psicológicas e apresenta a etapa de desenvolvimento do jogo correspondente a cada uma delas. 
Quadro 1 - Caracterização das idades psicológicas.

\begin{tabular}{|l|l|l|l|l|l|}
\hline \multicolumn{1}{|c|}{ Idade } & $\begin{array}{l}\text { Situação } \\
\text { social }\end{array}$ & $\begin{array}{c}\text { Linha do } \\
\text { desenvolvimento }\end{array}$ & $\begin{array}{c}\text { Atividade- } \\
\text { guia }\end{array}$ & $\begin{array}{c}\text { Etapa do } \\
\text { jogo }\end{array}$ & Neoformações \\
\hline $\begin{array}{l}\text { Primeiro } \\
\text { ano }\end{array}$ & "Nós" & Afetivo-emocional & $\begin{array}{l}\text { Comunicação } \\
\text { afetivo- } \\
\text { emocional }\end{array}$ & $\begin{array}{l}\text { Jogo de } \\
\text { manipulação } \\
\text { inespecífica }\end{array}$ & $\begin{array}{l}\text { Linguagem, } \\
\text { marcha, } \\
\text { comunicação } \\
\text { pessoal e psique } \\
\text { individual. }\end{array}$ \\
\hline $\begin{array}{l}\text { Primeira } \\
\text { infância }\end{array}$ & "Proto-eu" & $\begin{array}{l}\text { Técnico- } \\
\text { operacional }\end{array}$ & $\begin{array}{l}\text { Manipulação } \\
\text { objetal }\end{array}$ & $\begin{array}{l}\text { Jogo objetal } \\
\text { e início de } \\
\text { jogo } \\
\text { simbólico }\end{array}$ & $\begin{array}{l}\text { Significado } \\
\text { verbal e ações } \\
\text { objetais. }\end{array}$ \\
\hline $\begin{array}{l}\text { Pré- } \\
\text { escolar } \\
\text { "Eu- } \\
\text { reflexivo" }\end{array}$ & Afetivo-emocional & $\begin{array}{l}\text { Jogo } \\
\text { temático de } \\
\text { papéis } \\
\text { sociais }\end{array}$ & $\begin{array}{l}\text { Jogóde } \\
\text { papéis } \\
\text { sociais }\end{array}$ & $\begin{array}{l}\text { Imaginação, } \\
\text { sentido pessoal, } \\
\text { reflexão, } \\
\text { respeito a } \\
\text { regras, início da } \\
\text { atividade } \\
\text { voluntária e } \\
\text { compaixão. }\end{array}$ \\
\hline Escolar & $\begin{array}{l}\text { "Eu } \\
\text { consciente" }\end{array}$ & $\begin{array}{l}\text { Técnico- } \\
\text { operacional }\end{array}$ & $\begin{array}{l}\text { Atividade de } \\
\text { estudo }\end{array}$ & $\begin{array}{l}\text { Comportamento } \\
\text { voluntário e } \\
\text { capacidade } \\
\text { para } \\
\text { aprendizagem } \\
\text { individual } \\
\text { reórica. }\end{array}$ \\
\hline
\end{tabular}

Fonte: Adaptado de Chastinet (2019).

\section{A construção do Protocolo para Avaliação do Desenvolvimento da} Atividade Lúdica

O instrumento elaborado pelos autores contempla a faixa etária de zero a dez anos e pretende ser capaz de oferecer a psicólogos, pedagogos e educadores informações a respeito do desenvolvimento psíquico da criança em cada idade psicológica. A construção do protocolo esteve embasada teórica e metodologicamente na psicologia histórico-cultural e na teoria da atividade. Inicialmente se empreendeu uma revisão de literatura cujas principais fontes foram livros de autores da abordagem. Todo material consultado embasou a construção do protocolo e de seu manual teórico e prático. 
O protocolo está desenhado em cinco seções assim denominadas: 1. Avaliação da criança no primeiro ano (subdividido em quatro trimestres); 2. Avaliação do jogo objetal; 3. Avaliação do jogo simbólico; 4. Avaliação do jogo de papéis; 5. Avaliação do jogo de regras.

A primeira seção consiste em perguntas ao responsável, intervenções com a criança e observações de sua conduta que permitem avaliar principalmente o desenvolvimento psicomotor, a interação com o outro e o jogo de manipulação inespecífica, conforme manuais e livros consultados (CORIAT, 1991; POBLANO, 2003; PÉREZ, 2009; SOLOVIEVA; QUINTANAR ROJAS, 2012). Como exemplos de atividades, podemos listar: pôr algo na mão da criança para investigar sua preensão (primeiro trimestre), segurar a criança pelas mãos e conduzi-la a sentar-se verificando o alinhamento entre cabeça e corpo (segundo trimestre), sentar a criança em uma superfície firme e observar se é capaz de permanecer sentada liberando as mãos ao menos por um minuto para manipular objetos (jogo de manipulação inespecífica no terceiro trimestre), pôr a criança sentada e colocar alguns objetos coloridos um pouco afastados dela para observar se demostra interesse por eles e como faz para alcançá-los, deixá-la manipular os objetos por um tempo e observar suas ações (jogo de manipulação inespecífica no quarto trimestre).

A segunda e a terceira seção apresentam tarefas selecionadas e adaptadas de protocolos de avaliação neuropsicológica de pré-escolares e de avaliação da aquisição das ações objetais e da função simbólica (SOLOVIEVA; QUINTANAR ROJAS, 2014). Sua finalidade é avaliar o desenvolvimento das ações culturais e simbólicas com os objetos, respectivamente. Na investigação do jogo objetal, um exemplo de tarefa é solicitar que a criança utilize diferentes itens, como uma caneta, e perguntar: "O que se faz com a caneta?" e "Mostre como a boneca pode usar a caneta". Na verificação do jogo simbólico, um exemplo de atividade seria oferecer à criança um pente e um carrinho e propor a ela: "Você poderia usar o pente como se fosse um carrinho? Mostre como seria”.

A quarta seção avalia o desempenho da criança no jogo de papéis livre e estruturado, e foi planteada com base nos experimentos de Elkonin (2009) e na proposta pedagógica de organização e observação do jogo estruturado por Solovieva 
e Quintanar Rojas (2012). Nessa etapa o protocolo sugere, por exemplo, criar situações de jogo livre ou sugerido e observar elementos como: interação com o profissional, iniciativa, existência ou não de papeis e outros. O protocolo sugere possíveis formas de mediação como, no caso de a criança atribuir seu próprio nome ao personagem, dizer: "Esse é o seu nome de verdade. Na brincadeira teremos outro nome. Qual poderia ser?". Para avaliar o seguimento de regras durante o jogo, sugere-se propor: 1. Uma situação que infrinja a lógica da ação; 2. Uma situação que modifique o sentido do papel; 3. Uma ação estranha ao papel da criança.

Por fim, a quinta seção avalia a capacidade da criança de seguir regras preestabelecidas a partir de jogos de regras de dois tipos: de movimento e de mesa. A proposta apresentada foi elaborada com base em estudos de Leontiev (2010a, 2010b) e orientações de Solovieva e Quintanar Rojas (2012). Para a investigação, o profissional combina o jogo com a criança e revisa ou explica suas regras a ela. Enquanto jogam, observa se ela obedece às regras, quais infrações comete, se percebe o erro por si própria e se o jogo precisa ser constantemente interrompido, por exemplo.

Todas as etapas possuem indicações da correspondência das idades psicológicas em idades cronológicas, instruções, lista de materiais requeridos para a aplicação e espaços para registro de respostas às intervenções sugeridas, já que se disponibilizam algumas sugestões de mediação que podem ser úteis caso a criança não realize a atividade com autonomia. $\mathrm{O}$ manual do protocolo introduz $\mathrm{o}$ referencial teórico que fundamenta o instrumento e oferece recomendações e instruções para aplicação e interpretação dos dados.

Posteriormente à sua elaboração, o protocolo foi submetido à avaliação de especialistas em desenvolvimento infantil. Ao todo, cinco examinadoras (três Mestres e duas Doutoras) participaram na análise técnica do instrumento e receberam uma declaração de participação. Esse procedimento foi realizado em duas etapas: a primeira, em abril de 2015, com duas examinadoras, que tiveram a função de sugerir aprimoramentos à versão inicial do instrumento, e a segunda, em junho do mesmo ano, com três especialistas. Estas últimas emitiram um parecer final acerca do instrumento, indicando as últimas modificações necessárias. Para garantir melhor aproveitamento das críticas e 
sugestões e para assegurar a qualidade técnica do instrumento de avaliação, elaboramos uma ficha técnica de avaliação, considerados os requisitos do CFP vigentes no período de elaboração desse instrumento.

$\mathrm{Na}$ primeira análise técnica do instrumento, ressaltaram a clareza e coerência dos conceitos utilizados tanto em relação à teoria que tomamos por base, como em comparação a outros instrumentos de avaliação infantil. No que diz respeito à relevância e aplicabilidade do protocolo, foi apontada a importante lacuna a qual atende, em termos de avaliação do desenvolvimento infantil, e destacaram a relevância do instrumento para a avaliação clínica ou pedagógica, sendo recomendado para profissionais além do campo da psicologia, como pedagogos, fonoaudiólogos e assistentes sociais. Referiram como principais áreas de aplicação a psicologia clínica, neuropsicologia, psicologia da saúde e/ou hospitalar e educacional. O instrumento foi descrito como capaz de identificar os elementos mais relevantes do jogo em cada idade, aproximando-se do cotidiano e das brincadeiras infantis, utilizando instrumentos de fácil aquisição e baixo custo.

As principais sugestões, que conduziram às modificações mais importantes realizadas no protocolo, remetiam à padronização e revisão estrutural. Recomendaram pequenos ajustes de formatação e revisão gramatical. Sugeriram a simplificação de algumas instruções para facilitar a compreensão por crianças pequenas. Também sugeriram incluir outros materiais e brinquedos para ampliar as possibilidades de investigação do desenvolvimento de ações objetais e simbólicas. Sinalizaram modificações necessárias à organização estrutural do protocolo para garantir melhores condições de aplicação e interpretação dos dados. Todas as sugestões foram atendidas e o protocolo foi melhorado, passando-se, então, ao parecer final. Entre as examinadoras da segunda etapa, duas emitiram parecer de "aprovação" e uma delas de "aprovação com restrição".

A apresentação final do protocolo revisado foi publicada em livro em 2019: "Método de Avaliação e Estímulo da Atividade Lúdica - Abordagem HistóricoCultural” (MORAIS et al, 2019). Neste livro, um capítulo apresenta a estrutura geral do protocolo, considerando as 5 seções que o integram; outro capítulo apresenta as instruções para aplicação e interpretação dos dados; e, em outro 
capítulo, disponibilizam-se as folhas de aplicação e registro. O principal diferencial do instrumento quanto a sua aplicação e interpretação, em comparação a outros instrumentos de avaliação psicológica infantil, é a possibilidade de registrar três tipos de resposta: o que a criança realiza com autonomia, o que realiza com mediação e o que não consegue realizar nem mesmo com mediação.

Por entender que existem diferentes níveis de desenvolvimento mesmo na ZDP, foram considerados três níveis de mediação (VILLAR apud GLOZMAN, 2014). O primeiro corresponde ao que a criança realiza em resposta à mínima ajuda do adulto a partir de perguntas de orientação nas condições da atividade. $\mathrm{O}$ segundo corresponde à necessidade da criança de obter sugestões específicas ou até mesmo o modelo direto da ação por parte do adulto para conseguir realizar o que se propõe. O último nível seria aquele no qual a criança é mais dependente do adulto e só consegue atingir o objetivo da atividade se o adulto realiza junto com ela oferecendo todo o apoio e meios necessários.

A aplicação do instrumento está desenhada para oferecer a possibilidade de aplicar a seção que corresponde à idade psicológica esperada para a criança e, caso as atividades estejam completamente em sua ZDR, poder proceder a seção seguinte que corresponde à próxima idade psicológica. Da mesma forma, caso as atividades propostas ainda não sejam acessíveis à criança, é possível retornar à seção anterior e avaliar seu desempenho em comparação a uma idade psicológica prévia. É assim que o instrumento permite identificar a idade psicológica da criança e considerar o seu desenvolvimento segundo esse critério, diferentemente de outros instrumentos disponíveis que utilizam apenas o marco da idade cronológica como parâmetro.

\section{Contribuições do protocolo para a avaliação psicológica infantil nos âmbitos clínico e educativo}

As principais demandas da clínica neuropsicológica infantil são as dificuldades de aprendizagem e os problemas do desenvolvimento, os quais, pela ótica da avaliação tradicional, são classificados dentro de algum transtorno do neurodesenvolvimento, como especifica o DSM-5 (APA, 2014). Porém, as 
classificações com base na presença de um conjunto de sintomas, não traduzem de fato as particularidades do desenvolvimento da criança e contribuem para a sua patologização. Isso porque são organizadas a partir de sintomas amplos e gerais perdendo as particularidades de cada criança. Por outro lado, a avaliação neuropsicológica histórico-cultural tem o objetivo de identificar o desenvolvimento positivo ou negativo dos diferentes fatores neuropsicológicos que integram sistemas funcionais complexos necessários para a realização de qualquer atividade (SOLOVIEVA; QUINTANAR ROJAS, 2008). Esses fatores neuropsicológicos, que correspondem ao trabalho de áreas específicas do cérebro, se desenvolvem e se organizam em sistemas funcionais no curso dos diferentes tipos de atividade-guia em cada idade psicológica (LEONTIEV, 2009). Uma vez estabelecida a atividadeguia, o conteúdo de sua idade psicológica pode ser utilizado como mecanismo para estimular cada um dos fatores (MORAIS; CHASTINET; BORGES, 2018).

Por essa razão, a análise da atividade-guia é o fio condutor da avaliação neuropsicológica infantil. Identificar a dificuldade e o fator neuropsicológico que a explica, é o primeiro passo para a elaboração de um programa de estimulação, cuja eficácia dependerá principalmente do trabalho com a atividade-guia da idade psicológica do paciente (SOLOVIEVA; QUINTANAR ROJAS, 2017; AKHUTINA; ROMANOVA, 2017). Para tanto, faz-se necessária a construção de instrumentos fundamentados nesses conceitos e que permitam a compreensão da atividade-guia da criança, o que colabora com a caracterização da idade psicológica. Alguns estudos comprovam a utilidade de instrumentos desse tipo (BONILLA SÁNCHEZ; SOLOVIEVA; BARRETO, 2012; GONZÁLEZ MORENO; SOLOVIEVA; QUINTANAR ROJAS, 2016; SOLOVIEVA et al, 2018). Outros estudos também demonstram a eficácia dos programas de estimulação que se organizam sob este princípio e todos comprovam os benefícios da atividade lúdica (GONZÁLEZ-MORENO; SOLOVIEVA; QUINTANAR ROJAS, 2009; BONILLA SÁNCHEZ; SOLOVIEVA, 2016; GONZÁLES MORENO, 2017; GONZÁLES MORENO; SOLOVIEVA, 2017).

$\mathrm{Na}$ educação infantil, o conhecimento das características do desenvolvimento psíquico da criança nas diferentes idades psicológicas é de grande utilidade na capacitação dos professores para que a escola possa cumprir com seu 
propósito de oferecer um ensino organizado e sistemático que promova o desenvolvimento cultural das crianças. Ao contrário, práticas pedagógicas que não consideram esse princípio não promovem a verdadeira relação de ensinoaprendizagem que conduz ao desenvolvimento. Disponibilizar objetos e brinquedos para que as crianças manipulem e utilizem livremente sem nenhum tipo de orientação que permita a apropriação cultural desse objeto é uma prática que empobrece o desenvolvimento e é muito comum nas creches e escolas brasileiras (LAZARETTI; MAGALHÃES, 2019; SILVA, 2019).

Também existem muitos estudos que comprovam que programas curriculares que comtemplam a atividade de jogo na educação infantil, de forma organizada e na atividade colaborativa com o adulto, são mais exitosos no desenvolvimento das neoformações da idade pré-escolar, fundamentais para prevenção de dificuldades escolares futuras e para a preparação psicológica para a atividade de estudo, formando assim também as bases para o desenvolvimento do pensamento científico (LÁZARO et al, 2009; GARAIGORDOBIL; BURRUECO, 2011; GARCÍA; SOLOVIEVA; QUINTANAR ROJAS, 2013; GONZÁLEZ MORENO; SOLOVIEVA; QUINTANAR ROJAS, 2014; FLEER, 2019).

Desta forma, a elaboração deste Protocolo de Avaliação do Desenvolvimento da Atividade Lúdica foi pensada para servir às demandas de ambos contextos, clínico e educativo. Em ambos os cenários, é de grande utilidade avaliar o desenvolvimento da criança de acordo com sua idade psicológica, entendendo que as transformações qualitativas que caracterizam o desenvolvimento psíquico da criança são possíveis somente dentro da atividade conjunta com o outro, que dirige e orienta externamente a interação da criança com o mundo objetivo, físico e social. Essa proposta é diferente dos métodos de avaliações tradicionais da psicologia, assim como também diverge dos métodos de ensino tradicionais, os quais se centram nos processos de maturação biológica determinados pela idade cronológica. A posição aqui apresentada é a de que o fator determinante para o desenvolvimento estrutural e funcional do cérebro é a experiência cultural, mediada pela interação social. Por essa razão, a melhor forma de avaliar o 
desenvolvimento infantil é através da ZDP, o que reitera a contribuição que pretendemos oferecer com o instrumento apresentado.

\section{Considerações finais}

A importância do jogo (ou brincar) é vastamente reconhecida na literatura especializada. De acordo com Cotonhoto, Rossetti e Missawa (2019), ele tem sido alvo de investigações científicas em áreas como filosofia, educação, psicologia, sociologia e, de modo mais recente, na engenharia. As obras dos principais estudiosos da psicologia, a partir das mais diversas óticas, como Piaget, Bruner, Vygotski, Wallon e Elkonin, apresentam discussões sobre os diversos elementos no jogo que influenciam o desenvolvimento humano de maneira ampla. Desta forma, ganharam importância em todas as abordagens relativas à infância, como recurso para o desenvolvimento e a aprendizagem de habilidades cognitivas, sociais, afetivas e motoras. É considerado, entre pedagogos, professores e psicólogos, como um importante instrumento para a motivação e o desenvolvimento da linguagem oral, escrita, raciocínio lógico-matemático, entre outros (COTONHOTO; ROSSETTI; MISSAWA, 2019). Entretanto, nenhum dos 154 instrumentos favoráveis para avaliação infantil encontrados na lista do SATEPSI (entre psicométricos e projetivos), no momento do levantamento realizado pelos autores do presente trabalho, se dispõe a avaliar o desenvolvimento do jogo ou o utiliza como referência para investigar o desenvolvimento infantil. Desta forma, considera-se que o instrumento aqui proposto vem suprir uma carência significativa na área da avaliação psicológica de forma ampla (em diferentes contextos).

Outra característica que ele apresenta é a de ser o primeiro a basear-se na psicologia histórico-cultural enquanto referencial teórico. Isso faz com que possa ir mais além daquilo que os instrumentos psicométricos tradicionais se propõem a fazer, ou seja, levantar o que o avaliando consegue fazer sozinho (a ZDR). A proposta de instrumento exposta aqui deve permitir também a investigação do futuro do desenvolvimento infantil, aquilo que Vygotski denominou Zona de Desenvolvimento Proximal. Assim, além de caracterizar atrasos, adequações ou condutas mais avançadas de crianças em relação à idade 
cronológica e à norma (ZDR), espera-se que também esclareça sobre as novas aquisições do avaliando em termos de desenvolvimento do jogo e, como consequência, psicológico. Acreditamos que instrumentos desse tipo ampliem o trabalho do psicólogo (e outros profissionais que se dediquem à infância), enriquecendo o processo avaliativo e contribuindo com mais informações para a proposição de programas de intervenção e estimulação mais eficazes.

As dificuldades de aprendizagem e os problemas do desenvolvimento vêm sendo classificados dentro dos transtornos do neurodesenvolvimento, como se vê no DSM-5 (APA, 2014). Entretanto, consideramos que as classificações com base na presença de um conjunto de sintomas não traduzem de fato as particularidades do desenvolvimento da criança e contribuem para a sua patologização. Desta forma, os autores do instrumento aqui proposto esperam colaborar com uma práxis menos patologizante, pois a avaliação da ZDP objetiva compreender o que o sujeito está prestes a adquirir desde que lhe sejam oferecidos os meios adequados para garanti-lo. A forma de avaliar aqui proposta retira a necessidade de classificação do sujeito a partir de um rótulo encontrado na Classificação Internacional de Doenças (CID) ou no Manual Estatístico de Diagnóstico de Transtornos Mentais (DSM), ao mesmo tempo em que não deixa de compreendê-lo como indivíduo, pois compreende a ZDP de cada um de forma particular. O trabalho na ZDP permite a compreensão do indivíduo sem que seja necessário que se assuma o conceito prévio de que existe algum tipo de transtorno a ser identificado entravando seu desenvolvimento e/ou capacidade de aprendizagem. Desta forma, a investigação da ZDP não precisa ser realizada apenas em casos específicos em que se desconfie de transtornos, mas como instrumento para o planejamento e acompanhamento do desenvolvimento e da aprendizagem de qualquer criança em diferentes contextos.

A elaboração do Protocolo de Avaliação do Desenvolvimento da Atividade Lúdica deve servir às demandas dos contextos clínico e educativo, permitindo a compreensão do processo de desenvolvimento das crianças de acordo com sua idade psicológica a partir das atividades-guia e facilitando a elaboração de programas de estimulação sob este princípio. $\mathrm{Na}$ educação infantil, a caracterização do desenvolvimento psíquico dos alunos deve ser de grande utilidade na capacitação 
dos professores para que se possa oferecer um ensino organizado e sistemático que promova o desenvolvimento cultural infantil. Principalmente considerando que programas curriculares que comtemplam a atividade de jogo na educação infantil (de forma organizada e colaborativa) são exitosos no desenvolvimento das neoformações da idade pré-escolar, prevenção de dificuldades escolares futuras e para a preparação psicológica para a atividade de estudo.

Espera-se que o presente trabalho contribua com a prática da avaliação, seguindo o rigor técnico exigido pelo Conselho Federal de Psicologia, sem que se perca o conceito de avaliação mediada e participativa, que estimula o desenvolvimento psicológico, e que seja seguido por esforços semelhantes de construção de instrumentos que diminuam a lógica patologizante cada vez mais presente na sociedade moderna.

\section{Referências}

ABRANTES, A.; EIDT, N.M. Psicologia histórico-cultural e a atividade dominante como mediação que forma e se transforma: contradições e crises na periodização do desenvolvimento psíquico. Obutchénie, Uberlândia-MG, v.3, n.3, p.1-36, set./dez. 2019. DOI: https://doi.org/10.14393/OBv3n3.a2019-51694.

AKHUTINA, T.; ROMANOVA, A. Games as a tool for facilitating cognitive development. En Bruce, T., Hakkarainen, P. y Bredikyte, M. (edt.) The Routledge International Handbook of Early Childhood Play. New York: Routledge, 2017, p.357-375.

AMERICAN PSYCHIATRIC ASSOCIATION. Manual Diagnóstico e Estatístico de Transtornos Mentais - DSM-5. Tradução: Maria Inês Corrêa Nascimento et al. Porto Alegre: ARTMED, 2014.

BONILLA SÁNCHEZ, M. R.; SOLOVIEVA, Y. Evidencias de la formación de la función simbólica a través de la actividad de juego de roles sociales. Colombia: Cuadernos Hispanoamericanos de Psicología, v. 16, n. 1, p. 29-40, 2016. Disponível em: https://revistas.unbosque.edu.co/index.php/CHP/article/view/1967. Acesso em: 18 abr. 2018. DOI: https://doi.org/10.18270/chps..v16i1.1967.

BONILLA SÁNCHEZ, M. R.; SOLOVIEVA, Y.; BARRETO, N. R. J. Valoración del nivel de desarrollo simbólico en la edad preescolar. Revista CES Psicología, Colômbia, v. 5, n. 2, p. 56-69, 2012. Disponível em: https://www.redalyc.org/articulo.oa?id=423539471005. Acesso em: 30 mai. 2018. 
BOZHOVICH, L.I. Developmental Phases of Personality Formation in Childhood (I). Journal of Russian and East European Pstchology, Rússia, v. 42, n. 4, p. 35-54, 2004. DOI: https://doi.org/10.1080/10610405.2004.11059224.

BOZHOVICH, L.I. The Social Situation of Child Development. Journal of Russian and East European Pstchology, Rússia, v. 47, n. 4, p. 59-86, 2009.

CHAIKLIN, S. Age as a historical materialist concept in cultural-historical theory of human development. Obutchénie, Uberlândia, v.3, n.3, p.1-27, 2019. DOI: https://doi.org/10.14393/OBv3n3.a2019-51707.

CHASTINET, J. Desenvolvimento infantil. In: MORAIS, C. et al. Método de Avaliação e Estímulo da Atividade Lúdica. Abordagem Histórico-Cultural. São Paulo: Memnon, 2019, p. 7-18.

CONSELHO FEDERAL DE PSICOLOGIA (Brasília). Resolução no 09, de 25 de abril de 2018. Disponível em: https://site.cfp.org.br/wp-content/uploads/2018/04/ResoluçãoCFP-no-09-2018-com-anexo.pdf. Acesso em: 13 abr. 2020.

CORIAT, L. F. Maturação psicomotora no primeiro ano de vida da criança. São Paulo: Moraes LTDA, 1991.

COTONHOTO, L. A; ROSSETTI, C. B; MISSAWA, D. D. A. A importância do jogo e da brincadeira na prática pedagógica. Construção Psicopedagógica, São Paulo, v. 27, n. 28, p. 37-47, 2019. Disponível em:

http://pepsic.bvsalud.org/scielo.php?script=sci arttext\&pid=S1415-

69542019000100005\&lng=pt\&nrm=iso. Acesso em: 22 mai. 2020.

ELKONIN, D. B. Hacia el problema de la periodización del desarrollo en la edad infantil. In: QUINTANAR ROJAS, L.; SOLOVIEVA, Y. (org.) Las funciones psicológicas en el desarrollo del niño. México: Trillas, 2009a, p. 191-209.

ELKONIN, D. B. Psicologia do Jogo. São Paulo: Martins Fontes, 2009b.

FLEER, M. Conceptual PlayWorlds as a pedagogical intervention: Supporting the learning and development of the preschool child in play-based setting.

Obutchénie: Revista de Didática e Psicologia Pedagógica, Uberlândia, v.3, n.3, p.1-22, 2019. DOI: https://doi.org/10.14393/OBv3n3.a2019-51704.

GALPERIN, P. Y. El problema de la actividad en la psicología soviética. In: SOLOVIEVA, Y.; QUINTANAR ROJAS, L. La metodología formativa en la psicología histórico cultural. Tradução: Yulia Solovieva e Luis Quintanar Rojas. Madrid: Editorial EOS, 2019, p. 15-33. 
GARAIGORDOBIL, M.; BERRUECO, L. Effects of a Play Program on Creative Thinking of Preschool Children. The Spanish Journal of Psychology, Espanha, v. 14, n. 2, p. 608-618, 2011. Disponível em: https://www.researchgate.net/publication/51779808. Acesso em: 30 mai. 2019. DOI: https://doi.org/10.5209/rev sjop.2011.v14.n2.9.

GARCÍA, M. A.; SOLOVIEVA, Y.; QUINTANAR ROJAS, L. El desarrollo de neoformaciones a través del juego y del cuento en niños preescolares. Cultura y Educación, Espanha, v. 25, n. 2, p. 183-198, 2013. Disponível em:

https://www.researchgate.net/publication/261662343_El_desarrollo_de_neoformacione s_a_traves_del_juego_y_del_cuento_en_ninos_preescolares. Acesso em: 17 jun. 2018. DOI: https://doi.org/10.1174/113564013806631255.

GLOZMAN, J. Avaliação neuropsicológica de crianças. Tradução: Carla Anauate. São Paulo: MEMNON, 2014.

GONZÁLEZ MORENO, C. X. Intervención en un niño con autismo mediante el juego. Colombia: Revista de la Facultad de Medicina, v. 66, n. 3, p. 365-374, 2018. Disponível em: http://dx.doi.org/10.15446/revfacmed.v66n3.62355. Acesso em: 25 out. 2019. DOI: https://doi.org/10.15446/revfacmed.v66n3.62355.

GONZÁLEZ MORENO, C. X.; SOLOVIEVA; Y. Efectos del juego grupal en el desarrollo psicológico de un niño con Síndrome de Down. Pensamiento Psicológico, Colômbia, v. 15, n. 1, p. 127-145., 2017. Disponível em: doi:10.11144/Javerianacali.PPSI15-1.EJGD . Acesso em: 21 jul. 2018.

GONZÁLEZ MORENO, C. X.; SOLOVIEVA; Y.; QUINTANAR-ROJAS, L. Evaluación de la adquisición de las acciones perceptivas simbólicas en niños preescolares de Bogotá, Colombia. Summa Psicológica, Colômbia, v. 13, n. 1, p. 19-31, 2016. DOI: https://doi.org/10.18774/ summa-vol13.num1-284. Acesso em: 21 abr. 2019.

GONZÁLEZ MORENO, C. X.; SOLOVIEVA; Y.; QUINTANAR ROJAS, L. El juego temático de roles sociales: aportes al desarrollo en la edad preescolar. Avances en Psicología Latinoamericana, Colômbia, v. 32, n. 2, p. 287-308, 2014. DOI: https://doi.org/10.12804/apl32.2.2014.08. Acesso em: 21 abr. 2019.

GONZÁLEZ MORENO, C. X.; SOLOVIEVA; Y.; QUINTANAR ROJAS, L. La actividad de juego temático de roles en la formación del pensamiento reflexivo en preescolares. Magis - Revista Internacional de Investigación en Educación, v. 2, n. 3, p. 173-190, 2009. Disponível em: https://www.redalyc.org/articulo.oa?id=281021558010. Acesso em: 19 ago. 2019. DOI: http://dx.doi.org/10.15446/revfacmed.v63n2.47983.

LAZARETTI, L. M. Danil Borisovich Elkonin: A vida e as produções de um estudioso do desenvolvimento humano. In: LONGAREZI, A. M.; PUENTES, R. V. (org.) Ensino desenvolvimental: Vida, pensamento e obra dos principais representantes russos. Uberlândia: EDUFU, 2013, p. 203-231. 
LAZARETTI, L. M.; MAGALHÃES, G. M. A primeira infância vai à escola: em defesa do ensino desenvolvente para todas as crianças. Obutchénie: Revista de Didática e Psicologia Pedagógica, Uberlândia, v. 3, n. 3, p. 1-21, 2019. Disponível em: http://dx.doi.org/10.14393/OBv3n3.a2019-51702. Acesso em: 17 abr. 2020.

LÁZARO, E. et al. Actividades de Juego y cuento para el desarrollo psicológico del niño preescolar. Bogotá: Revista Internacional Magisterio, v. 7, n. 37, p. 81-85, 2009. Disponível em:

http://cmas.siu.buap.mx/portal_pprd/work/sites/neuropsicologia/resources/LocalC ontent/108/2/Art_Juego_cuento.pdf. Acesso em: 19 ago. 2019.

LEONTIEV, A.N. La importancia del concepto de actividad objetal para la psicología. En Quintanar, L. y Solovieva, Y. Las funciones psicológicas en el desarrollo del niño. México: Trillas, 2009, p.54-63.

LEONTIEV, A.N. Os princípios psicológicos da brincadeira pré-escolar. In: VIGOTSKII, L.S.; LURIA A.R.; LEONTIEV, A. N. Linguagem, desenvolvimento e aprendizagem. Tradução: Maria da Venha Villalobos. São Paulo: Ícone, 2010a, p. 119-142.

LEONTIEV, A.N. Uma contribuição à teoria do desenvolvimento da psique infantil. In: VIGOTSKII, L.S.; LURIA A.R.; LEONTIEV, A. N. Linguagem, desenvolvimento e aprendizagem. Tradução: Maria da Venha Villalobos. São Paulo: Ícone, 2010b, p. 59-83.

MORAIS, C. et al. Método de Avaliação e Estímulo da Atividade Lúdica Abordagem Histórico-Cultural. São Paulo: Memnon, 2019.

MORAIS, C.; CHASTINET, J.; BORGES, C. Estimular para prevenir numa abordagem histórico-cultural: propostas para a educação infantil. Obutchénie: Revista de Didática e Psicologia Pedagógica, v. 2, n. 3, p. 740-764, 2018. DOI: https://doi.org/10.14393/OBv2n3.a2018-47443.

PÉREZ, M. C. S. Valoracíon neuroconductual del desarrollo del lactante. CBS: México, 2009.

POBLANO, A. Detección y estimulación tempranas del niño con daño neurológico. ETM: México, 2003.

PRESTES, Z. R. Quando não é quase a mesma coisa. Análise de traduções de Lev Semionovitch Vigotski no Brasil. Repercuções no campo educacional. 2010. Tese (Doutorado em Educação) - Faculdade de Educação, Universidade de Braília, Brasília, 2010. 
QUINTANAR ROJAS, L.; SOLOVIEVA, Y. Avaliação das neoformações psicológicas na idade pré-escolar. Tradução: Caio Morais e Jamile Chastinet. Uberlândia: EDUFU, 2013. DOI: https://doi.org/10.14393/edufu-978-85-7078-361-5.

SANTOS, A. A. A. et.al. Avaliação Psicológica: Diretrizes na Regulamentação da Profissão. Brasília-DF: CFP, 2010.

SATEPSI. Conselho Federal de Psicologia. Testes Favoráveis. Disponível em: http://satepsi.cfp.org.br/testesFavoraveis.cfm. Acesso em: 10 abr. 2020.

SHEINA, E., SMIRNOVA, E.; RYABKOVA, I. The developmental potential of toys and games. In: BRUCE, T., HAKKARAINEN, P.; BREDIKYTE, M. (ed.) The Routledge International Handbook of Early Childhood Play. New York: Routledge, 2017, p. 305-312. DOI: https://doi.org/10.4324/9781315735290-28.

SILVA, C. R. O desenvolvimento humano na perspectiva histórico-cultural: relações entre a organização das condições de ensino e a produção da queixa escolar na educação infantil. Obutchénie, Uberlândia, v. 3, n. 3, p. 1-29, 2019. DOI: https://doi.org/10.14393/OBv3n3.a2019-51703.

SOLOVIEVA, Y.; GONZÁLEZ MORENO, C. X.; QUINTANAR ROJAS, L. Indicators of reflection during acquisition of symbolic actions in preschool Colombian children. Psychology in Russia. State of the Art, Rússia, v. 8, n. 2, p. 61-72, 2015. Disponível em: http://psychologyinrussia.com. Acesso em: 16 jul. 2018. DOI: https://doi.org/10.11621/pir.2015.0206.

SOLOVIEVA, Y.; QUINTANAR ROJAS, L. Metodología del estudio psicológico desde el enfoque histórico-cultural. In: SOLOVIEVA, Y.; QUINTANAR ROJAS, L. (org). La metodología formativa en la psicología histórico-cultural. Madrid: EOS Psicología, 2019, p.181-204.

SOLOVIEVA, Y.; QUINTANAR ROJAS, L. Aproximación histórico-cultural: Fundamentos teórico-metodológicos. In: ESLAVA-COBOS, J. et. al. (org.) Los trastornos del aprendizaje: perspectivas neuropsicológicas. Bogotá: Cooperativa editorial Magisterio, Instituto Colombiano de Neurociencias, Benemérita Universidad de Puebla, 2008, p. 147-181.

SOLOVIEVA, Y.; QUINTANAR ROJAS, L. Evaluación del desarrollo para niños preescolares menores. México: Benemérita Universidad Autónoma de Puebla, 2014.

SOLOVIEVA, Y.; QUINTANAR ROJAS, L. La actividad de juego en la edad preescolar. México: Trillas, 2012. 
SOLOVIEVA, Y.; QUINTANAR ROJAS, L. (2017). Syndromic analysis in child neuropsychology: a case study. Psychology in Russia: State of the Art, v. 10, n. 4, p. 172-184. Disponível em:

http://psychologyinrussia.com/volumes/pdf/2017_4/psych_4_2017_15.pdf.

Acesso em: 19 dez. 2017. DOI: https://doi.org/10.11621/pir.2017.0415.

SOLOVIEVA, Y. et al. Valoración de la actividad objetal en una muestra de niños mexicanos de 13 a 52 meses. México: Revista de Psicología y Ciencias del comportamiento de la Unidad Académica de Ciencias Jurídicas y Sociales, v. 9, n. 2, p. 80-94, 2018. DOI: https://doi.org/10.29365/rpcc.20181207-72. Acesso em: 10 jan. 2020.

VIGOTSKI, L. S. Fundamentos da Pedologa [sic] de L. S. Vigotski. In: PRESTES, Z.; TUNES, E. 7 aulas de L. S. Vigotski. Sobre os fundamentos da pedologia.

Tradução: Zoia Prestes, Elizabeth Tunes e Cláudia da Costa Guimarães Santana. Rio de Janeiro: E-papers, 2018, p. 17-147.

VIGOTSKI, L. S. Fragmento das anotações de Vigotski para conferências sobre psicologia infantil. In: ELKONIN, D. B. Psicologia do jogo. Tradução: Álvaro Cabral. São Paulo: WMF Martins Fontes, 2009, p. 423-433.

VIGOTSKY, L. S. A Formação Social da Mente. Tradução: José Cipolla Neto, Luís Silveira Menna Barreto e Solange Castro Afeche. São Paulo: Martins Fontes, 2007.

VYGOTSKI, L. S. Obras Escogidas - IV. Problemas del adolescente. Problemas de la psicología infantil. Tradução: Lydia Kuper. Madrid: Machado Nuevo Aprendizaje, 2012a.

VYGOTSKI, L. S. Obras Escogidas - III. Problemas del desarrollo de la psique. Tradução: Lydia Kuper. Madrid: Machado Nuevo Aprendizaje, 2012b.

VYGOTSKI, L.S. Obras Escogidas - I. El significado histórico de la crisis de la Psicología. Tradução: José Maria Bravo. Madrid: Machado Nuevo Aprendizaje, 2012c. 